\title{
Designing for Multispecies Collaboration and Cohabitation
}

\author{
Szu-Yu (Cyn) Liu \\ Indiana University \\ Bloomington, IN 47408 USA \\ cynliu@iu.edu
}

\section{ABSTRACT}

Human-nature interaction, joining the agendas of sustainable interaction design and nonanthropocentric $\mathrm{HCl}$, takes up the challenges presented by climate change and environmental crisis. My dissertation focuses on studying sustainable farming practices through posthuman concepts to experiment ways of supporting multispecies collaborative works. Specifically, my research aims to discover and develop alternative design paradigms and practices for sustaining both human-nature collaboration, cohabitation, and co-creation.

\section{KEYWORDS}

Human-nature interaction; posthuman; decentering humans; multispecies; sustainable $\mathrm{HCl}$.

\section{INTRODUCTION}

My research focuses on human-nature interaction and sustainable agriculture to attend to environmental challenges. Specifically, I engage in posthuman theories and investigate through on the ground experimental farming, collaborative food making, decomposition in agriculture and

Permission to make digital or hard copies of part or all of this work for personal or classroom use is granted without fee provided that copies are not made or distributed for profit or commercial advantage and that copies bear this notice and the full citation on the first page. Copyrights for third-party components of this work must be honored. For all other uses, contact the Owner/Author(s).

CSCW'19 Companion, November 9-13, 2019, Austin, Texas, USA

(c) 2019 Copyright is held by the author/owner(s).

ACM ISBN 978-1-4503-6692-2/19/11.

https://doi.org/10.1145/3311957.3361861 


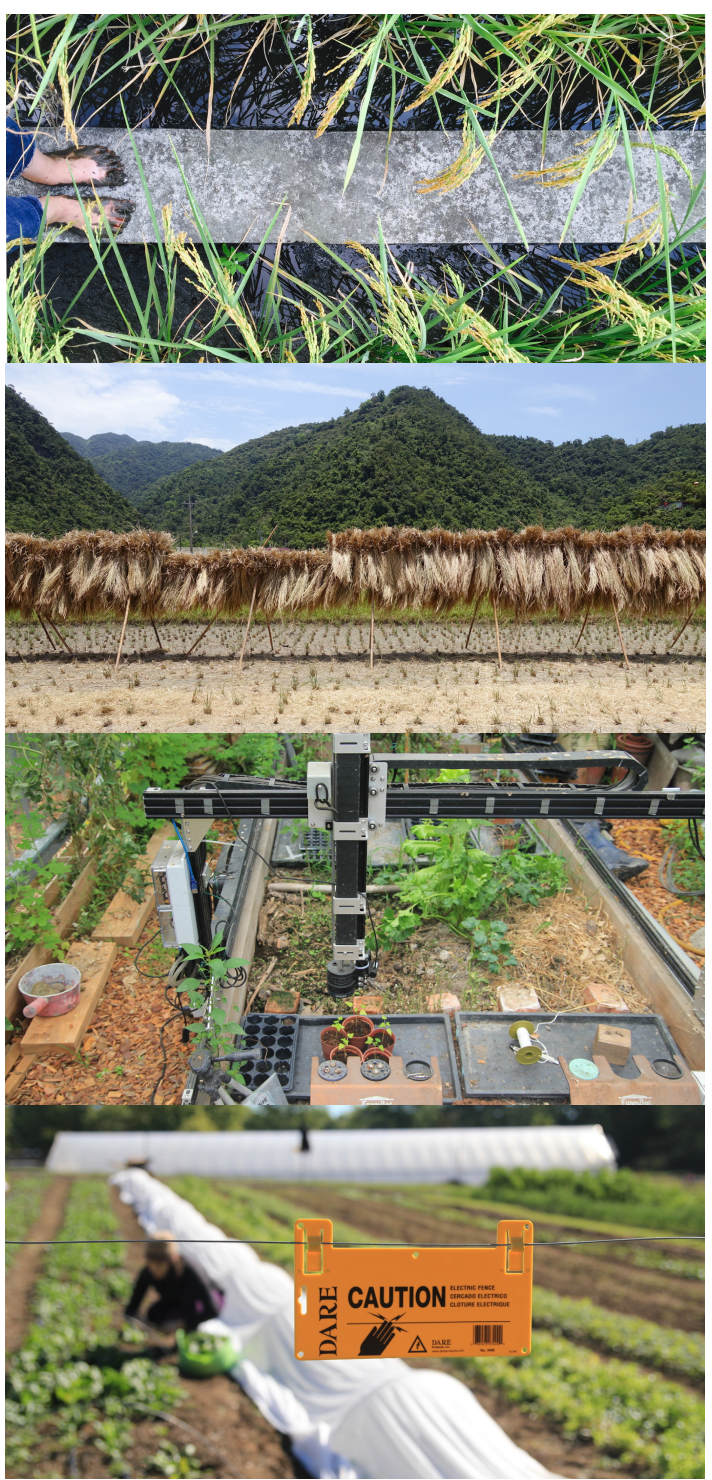

Figure 1: Photos taken during my ethnographic fieldwork in small-scale farms in Yilan, Taiwan and Indiana, USA. design to explore ways of working with nature, as opposed to controlling or working against it. Building on my on-going ethnographic study on small-scale, sustainable farming practices in Taiwan and Indiana (figure 1), my work proposes decentering the human in design to envision more responsible ways of engaging in technological interventions. This line of research has led to a series of publications in prestigious SIGCHI venues, including CHI2019 [14], TEI2019 [12], DIS2018 [11], and LIMITS2018 [13]. In Summer, 2019, my three-month research internship program at Microsoft Research focuses on creating and deploying environmental sensing technologies to support environmental sustainability, public health, and social equity in urban spaces.

\section{CONTEXT AND MOTIVATION}

Prior to my doctoral studies, I was a product designer at an international personal computer design firm. Having witnessed truck after truck of hardware and electronic waste being transported to landfills every year, I am committed to forging together a stronger connection between design practices and environmental sustainability. I build on the values and frameworks of sustainable $\mathrm{HCl}$ but push for a broader definition of sustainability by bringing to the forefront the moments "when species meet" [5]; I am interested in exploring the possibilities and challenges in decentering the human in interaction design.

To do so, I turn to posthuman theories which consider humans, nonhumans, culture, and nature as intricately entangled and thus challenges the taken-for-granted ontological boundaries [6,7]. My research draws on anthropologist Anna Tsing's work, especially her theoretical concept, "arts of noticing," to see "the divergent, layered, and conjoined projects that make up worlds" [20:22], to cultivate the ability to acknowledge and simultaneously step in and out of familiar frames of reference [9], and to imagine alternative futures by questions about "what is and what can be" [1].

\section{RELATED WORKS AND MY RESEARCH OUTPUT}

Two interaction design research communities emerged with the attempt to address challenges associated with environmental crisis through design: sustainable interaction design and nonanthropocentric $\mathrm{HCl}$. In the former, studies show increasing interests moving from individual persuasive technological design towards addressing the broader socioenvironmental challenges $[2,16]$. More recently, scholars in nonanthropocentric $\mathrm{HCl}$ reflect on the limits of human-centric design and argue the need to establish an alternative design agenda that encompasses a multispecies worldview [3,19]; this body of research provides insight into nurturing interspecies collaboration [4], cohabitation [18], and collaborative survival $[8,10]$.

Posthuman concepts are particularly useful in resisting falling into habitual anthropocentric perspectives by "considering the social as a tissue of associations between humans, nonhumans, and objects working in the realisation of new relational formations." [17:7]. However, the ability to move from automatic perceptions toward seeing interspecies dependency is not easily cultivated; to Tsing, to "notice differently" requires shifting attention between multiple threads of a relationship [20]. 


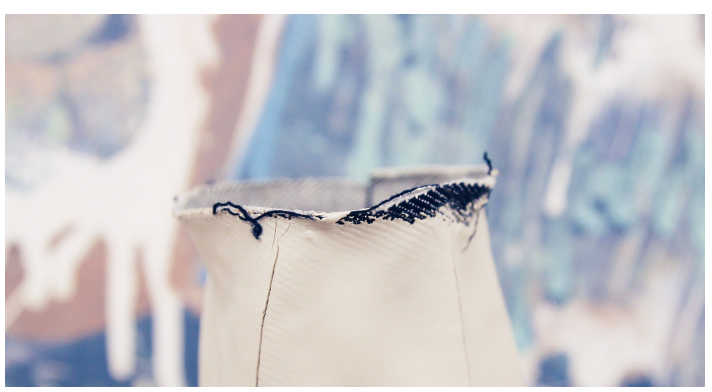

Figure 2: The process of decomposition and the notion of natureculture co-creation is the guiding principle for a series of ceramics experiments.

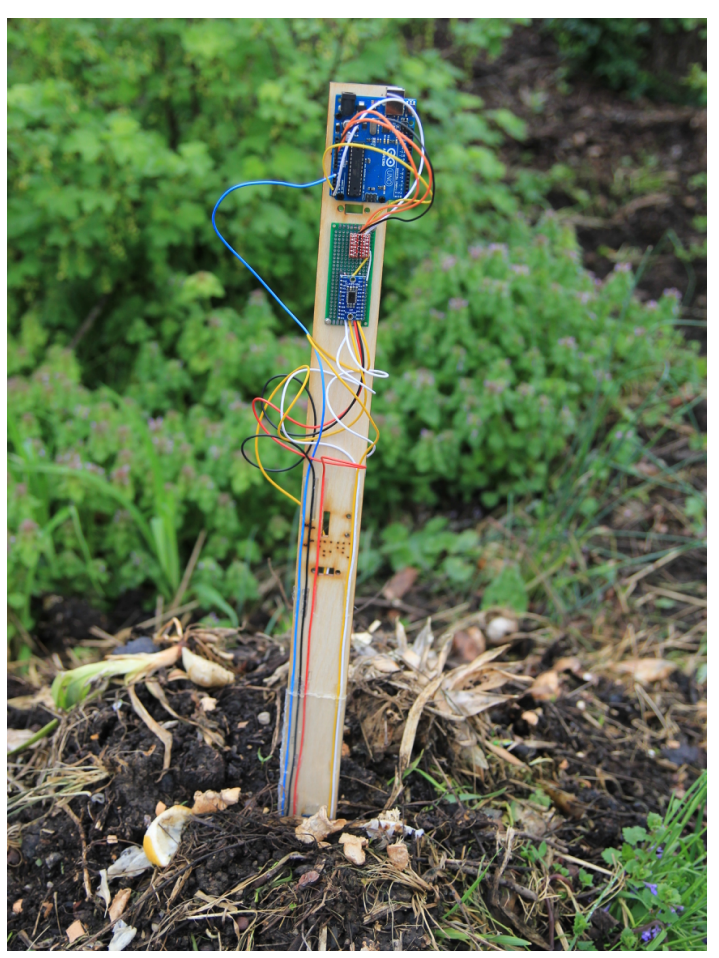

Figure 3: Tracking and gathering conditions of a compost pile with Ode to Soil first prototype.
With the interest in increasing human-nature collaboration and cohabitation, I focus on translating abstract posthuman concepts into more trackable interaction design interventions and actionable design strategies. For example, in [12], my co-authors and I unpack through Haraway's posthuman theory natureculture the process of decomposition. Through a series of design curation, analysis, and experiment, we propose the concept of "scaffolding" for those who are interested in natureculture cocreation. In $[13,14]$, we report our 2-year ethnography working alongside with small-scale farmers and how we learn to see weeds and pests as companions. Through embodied understanding of the earth, we reflect on ways of cultivating intimacy with the biosphere with and through technology.

In [11], my co-authors and I combine together visual thinking and critical reflection to "see" the theoretical concept of natureculture by capturing through photographs different interfaces of human-nature interaction. In [12], the posthuman concept natureculture is further consolidated through a series of ceramics experiments (figure 2). Very recently, I experiment embodied knowledge as yet another way of knowing [14]: in reflecting the symbiotic encounters, I work with eco-friendly farmers, animals, plants, and soil, I look into nontraditional users (e.g., nonhumans) and emerging forms of uses (e.g., interactions between human and other species) to help open a design space for technological interventions. In DIS2019, I am co-organizing a workshop to explore and develop methodological approaches for $\mathrm{HCl}$ researchers and practitioners to "notice differently" and envision ways of engaging in nontraditional and marginal users through technological interventions [15].

\section{RESEARCH GOALS, QUESTIONS, AND METHODS}

When human activities render resource exhaustion, species extinction, and other forms of conflicts between humans and the environment, new ways of noticing, responding, and imagining are needed to move toward to preferable futures. Specifically, my research questions include: (1) How may interaction designers incorporate natural phenomenon and nonhuman actors into their creative processes? (2) What can design practitioners learn from the interaction between humans and nonhumans to inform design practices? (3) How may technological interventions support more sustainable, ethical, aesthetic, and intimate forms of human-nature interaction? The methods involve in my dissertation research are multi-fold, including qualitative social science methods (e.g., ethnography, interviewing, and observation), art-based inquiry methodologies (e.g., research through design), and approaches originated from the humanities (e.g., interaction criticism and close reading).

My on-going ethnography focuses on sustainable farming experiments, including eco-friendly farming, small-scale farming, organic farming, and AgTech. Common across these practices is the farmers' commitment in exploring the alternatives to industrial agriculture, with a particular focus on reducing the use of pesticides to integrate more harmonious between land, people, environment, and resources. In these alternative farming practices, the farm is not so much a controlled system, but an assemblage characterized by multiple systems or rationalities always evolving and changing. By working alongside with the farmers, I reflect on posthumanist values and learn to "notice differently." 


\section{CONTRIBUTIONS AND GOALS FOR CSCW DC} My goal for the CSCW DC is to receive feedback on reworking existing $\mathrm{HCl}$ research methods for multispecies collaboration as well as leveraging other disciplinary input (anthropology, STS, environmental science) for biodiversity research in $\mathrm{HCl} / \mathrm{CSCW}$. I hope to contribute to the CSCW DC by sharing my experience in designing and theorizing multispecies collaboration.

\section{ACKNOWLEDGMENTS}

I thank my PhD advisors, Jeffrey Bardzell and Shaowen Bardzell, for their all-time tremendous mentorship and unconditional supports. I'm thankful for my committee members, Eli Blevis and Barbara Dennis for their insightful feedback. I'm grateful for the inspirational conversations I have with Justin Cranshaw and Asta Roseway at Microsoft Research in supporting my dissertation work. This research is supported in part by Taiwan's Ministry of Education and the NSF under award \#1513604.
Building on my previous ethnographic and design works, I am currently designing an acoustic probe, "Ode to Soil", that tracks different attributes of compost piles (e.g., temperature, humidity, biometric movement) and translates the digital reads into musical notes (figure 3). The design explores a more embodied and aesthetic form of human-nature interaction and collaboration that attunes human senses to the rhythms of the natural environment. The next stage of my dissertation research involves deploying this acoustic probe to examine how human-nature engagement might unfold to cultivate biodiversity and sustainability.

\section{REFERENCES}

[1] Eli Blevis. 2018. Seeing What Is and What Can Be: On Sustainability, Respect for Work, and Design for Respect. In CHI '18, Paper No. 370

[2] Jaz Hee-jeong Choi and Eli Blevis. 2010. $\mathrm{HCl} \&$ sustainable food culture: A design framework for engagement. In NordiCHI '10, 112-117.

[3] Rachel Clarke, Sara Heitlinger, Ann Light, Laura Forlano, Marcus Foth, and Carl Disalvo. 2019. More-Than-Human Participation: Design for Sustainable Smart City Futures. Interactions, 60-63.

[4] Laura Forlano. 2016. Decentering the Human in the Design of Collaborative Cities. Design Issues 32, 3: 42-54.

[5] Donna J. Haraway. 2008. When Species Meet. University of Minnesota Press, London.

[6] Donna J Haraway. 2016. Staying with the Trouble: Making Kin in the Chthulucene. Duke University Press.

[7] Joanna Latimer and Mara Miele. 2013. Naturecultures? Science, Affect and the Non-human. Theory, Culture \& Society 30, 7-8: 5-31.

[8] Ann Light, Alison Powell, and Irina Shklovski. 2017. Design for Existential Crisis in the Anthropocene Age. In C\&T '17.

[9] Silvia Lindtner, Shaowen Bardzell, and Jeffrey Bardzell. 2018. Design and Intervention in the Age of "No Alternative." Proceedings of the ACM on Human-Computer Interaction 2, CSCW: Article 109.

[10] Jen Liu, Daragh Byrne, and Laura Devendorf. 2018. Design for Collaborative Survival: An Inquiry into Human-Fungi Relationships. In $C H I^{\prime} 18,1-13$

[11] Szu-Yu (Cyn) Liu, Jeffrey Bardzell, and Shaowen Bardzell. 2018. Photography as A Design Research Tool into Natureculture. In DIS '18, 777-789.

[12] Szu-Yu (Cyn) Liu, Jeffrey Bardzell, and Shaowen Bardzell. 2019. Decomposition as Design: Co-Creating (with) Natureculture. In TEI' 19

[13] Szu-Yu (Cyn) Liu, Shaowen Bardzell, and Jeffrey Bardzell. 2018. Out of Control: Reframing Sustainable HCI Using Permaculture. In LIMITS '18, Article No. 2.

[14] Szu-Yu (Cyn) Liu, Shaowen Bardzell, and Jeffrey Bardzell. 2019. Symbiotic Encounters: HCI and Sustainable Agriculture. In $\mathrm{CHI}$ '19.

[15] Szu-Yu (Cyn) Liu, Jen Liu, Kristin Dew, Patrycja Zdziarska, Maya Livio, and Shaowen Bardzell. 2018. Exploring Noticing as Method in Design Research. In DIS '18.

[16] Juliet Norton, Nico Herbig, Lynn Dombrowski, Ankita Raturi, Bonnie Nardi, Sebastian Prost, Samantha McDonald, Daniel Pargman, Oliver Bates, Maria Normark, and Bill Tomlinson. 2017. A grand challenge for HCI: food + sustainability. Interactions $24,50-55$.

[17] María Puig de la Bellacasa. 2010. Ethical doings in naturecultures. Ethics, Place and Environment 13, 2: 151-169.

[18] Nancy Smith, Shaowen Bardzell, and Jeffrey Bardzell. 2017. Designing for Cohabitation: Naturecultures, Hybrids, and Decentering the Human in Design. In CHI'17, 1714-1725.

[19] Vanessa Thomas; Christian Remy, and Oliver Bates. 2017. The Limits of HCD: Reimagining the Anthropocentricity of ISO 9241-210. In LIMITS '17.

[20] Anna Lowenhaupt Tsing. 2015. The Mushroom at the End of the World. Princeton University Press. 